Alaa' N A1-Saraj

BDS, MSc (Asst. Lec.)

\section{The Effect of Mixing Technique and Methods on Some Physical Properties of Dental Stone}

Department of Prosthetic Dentistry

College of Dentistry, University of Mosul

\begin{abstract}
الخحلاصة
الأهداف: تحدف الدراسة إلى تقييم تأثر طرائق الخلط المختلفة لمادة الحجر السني و النسب المختلفة للماء على المسحوق على المقاومة الانضغاطية والصلادة السطحية.

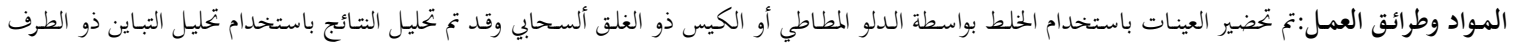

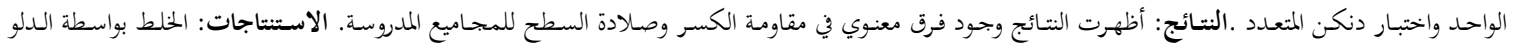

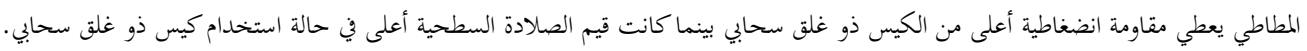

\begin{abstract}
Aims: The study aims to evaluate the effect of mixing techniques and water powder ratio on the compressive strength and surface hardness of dental stone. Materials and Methods: The samples of compressive strength and surface hardness testes were prepared by 2 water powder ratio the ratio recommended by manufacture and that used by dentists and 2 mixing methods rubber bowl and spatula and zip-lock bag. The collected data analyzed using one sample t-test, ANOVA and Duncans' multiple range test at $p \geq 0.5$. Results: The results showed statistically significant difference in compressive strength and surface hardness among tested groups. Conclusion: Mixing by rubber bowl and spatula and using water powder ratio recommended by manufacturer gives the highest compressive strength value while using zip-lock bag give a higher surface hardness value than rubber bowl and spatula.
\end{abstract}

Key wards :dental stone, mixing technique, water powder ratio, surface hardness, compressive strength.

Al-Saraj AN. The Effect of Mixing Technique and Methods on Some Physical Properties of Dental Stone. Al-Rafidain Dent J. 2013; 13(1): 170-175.

Received: 4/12/2011 Sent to Referees: 7/12/2011

Accepted for Publication: 25/3/2012

\section{INTRODUCTION}

The mixing or spatulation of many dental materials is a troublesome and unpredictable process, because of the introduction of porosities caused by the nature of the water/ powder or paste/paste interaction. Such problems may also result from the mechanical action of the mixing device. Ideally, completely homogenous materials would be desirable. $^{(1)}$ The dental impression and model materials are very important to preserve the physical evidence present on crime scene such as shoeprints tire marks and inanimate materials such as cheese to later on compare with the teeth of a suspected and make a conclusion. ${ }^{(2-4)}$ For casting threedimensional prints, two main techniques for mixing the dental stone with water are usually applied:
- Using a bucket to stir a premeasured amount of dental stone added to a premeasured amount of water.

- A premeasured amount of dental stone is kept in a zip-lock bag and a premeasured amount of water is added later. ${ }^{(5)}$

Dental cast materials should ideally be fluid at the time it is poured into the impression so that fine detail can be recorded. The set material should be sufficiently strong to resist the accidental fracture and hard enough to resist the abrasion during the carving of a wax pattern. ${ }^{(6)}$

The theoretical amount of water required for $100 \mathrm{gm}$ of gypsum products to reacts chemically with the available calcium sulfate hemihydrates particle is $18.61 \mathrm{ml} .^{(7)}$ However, this ratio would not produce a workable mix due to the absorption of water 
within the pores of hemihydrates. ${ }^{(8)}$ The actual amount of water necessary to mix the calcium sulfate hemihydrates is $28-32 \mathrm{ml}$ which is greater than the amount used for chemical reaction. ${ }^{(9)}$

The water powder ratio for dental stone is $0.30 \mathrm{ml} / \mathrm{gm}(20-35 \mathrm{ml}$ of water for each $100 \mathrm{gm}$ of powder). ${ }^{(10)}$

Water powder ratio plays a significant role in the intercrystalline package, increasing the relative intercrystalline space, leading to a greater space between nuclei of crystallization. ${ }^{(10-12)}$

The strength of gypsum products depends, primarily, on the porosity of the set material and the time for which the material is allowed to dry out after setting. The porosity, and hence the strength, is proportional to the W/P ratio .Since stone is always mixed at a lower water powder ratio than plaster it is less porous and consequently much stronger and harder. ${ }^{(6)}$

Surface hardness is very essential factor in evaluating dental stone. it is generally felt that the harder the stone the better will be the wear resistance and destruction during the fabrication and finishing of the pattern or casting. ${ }^{(13)}$

\section{MATERIALS AND METHODS}

This study is started by a simple questioner distributed randomly to (120) dentists working in College of Dentistry at University of Mosul, the questioner include the following questions:

1.When you mix dental stone do you measure the powder and water according to the manufacturer instructions ?

a. Yes.

b. No.

2.During your mixing, do you :

a. Add powder to water .

b. Add water to powder.

3.Do you know a method for mixing dental stone other than rubber bowl and spatula (if your answer is yes mention it)?

a. Yes .

b.No.

The questioner showed the following; $9.1 \%$ of the dentists included in this survey was measuring powder and water according to manufacturer instructions and $90.9 \%$ didn't measure ;50.4 \% was adding powder to water and $49.6 \%$ add water to powder $100 \%$ of the dentist that included in the study didn't know other mixing method.

From this $90.9 \%$ of dentists who don't measure powder and water according to manufacturer instructions 20 dentists were randomly selected in the following criteria ; have M.Sc. degree and having clinical practice in a private clinic at least for 5 years, then each dentist were given 100gmof dental stone (Elite stone Zehrmack)/Italy) which is measured by electrical digital balance (A\&d company limited, Japan) $100 \mathrm{ml}$ of water which is measured by graduated cylinder, and were asked to mix part of it as they used to do on their daily practice. Then the rest of water and dental stone powder were measured and reduced from the original amount to determine the exact amount of powder and water they were used and from their mean a water powder ratio were determined to be used on preparing the samples for compressive strength and surface hardness tests.

Physical properties tests

Sixty four samples were prepared thirty two samples for each test two mixing methods; either rubber bowl and spatula ${ }^{(6)}$ or ziplock bag ${ }^{(5)}$ in which the stone is mixed by massaging and kneading the bag for $1 \mathrm{~min}$ until the water and the dental stone seemed completely mixed, and no lumps were observed.

Each of these two methods was preformed either by adding water to powder or adding powder to water and two powder water ratios were used $25 \mathrm{ml} / 100 \mathrm{gm}$ that recommended by manufacturer and 27.89 $\mathrm{ml} / 100 \mathrm{gm}$ that used by dentists. The mixing groups are as follow; $M$ powder /water ratio of manufacturer, D powder/water ratio of dentists, W: put water first, P:put powder first, R: using rubber bowl and spatula in mixing, Z:using zip-lock bag in mixing so MWR group meant using powder/water ratio of manufacturer and putting water first and mixing by rubber bowl and spatula and so on. 
The samples were prepared using split molds in the following dimensions: $30 \mathrm{~mm}$ length and $20 \mathrm{~mm}$ diameter for surface hardness test and in the dimensions of $40 \mathrm{~mm}$ length and $20 \mathrm{~mm}$ diameter ${ }^{(14)}$ for compressive strength. During pouring the samples moulds vibrated gently while being filled using electrical vibrator (Qualy Dental, England). The samples removed from the split molds 30 minutes after pouring and stored in desiccators for 24 hours before testing.
The compressive strength test was done by crushing the samples by using uniaxial compressive machine (ELE/ England) at rate of 100divisions /minute that measure load in kilo Newton then it was converted to kilo gram and the compressive strength was calculated according to the following equation compressive strength $=$ Load $(\mathrm{Kg})$ /Area $\left(\mathrm{cm}^{2}\right)$.

Where surface area $=$ Area of circle $=3.14 \mathrm{~cm}^{2}$ Figure(1).

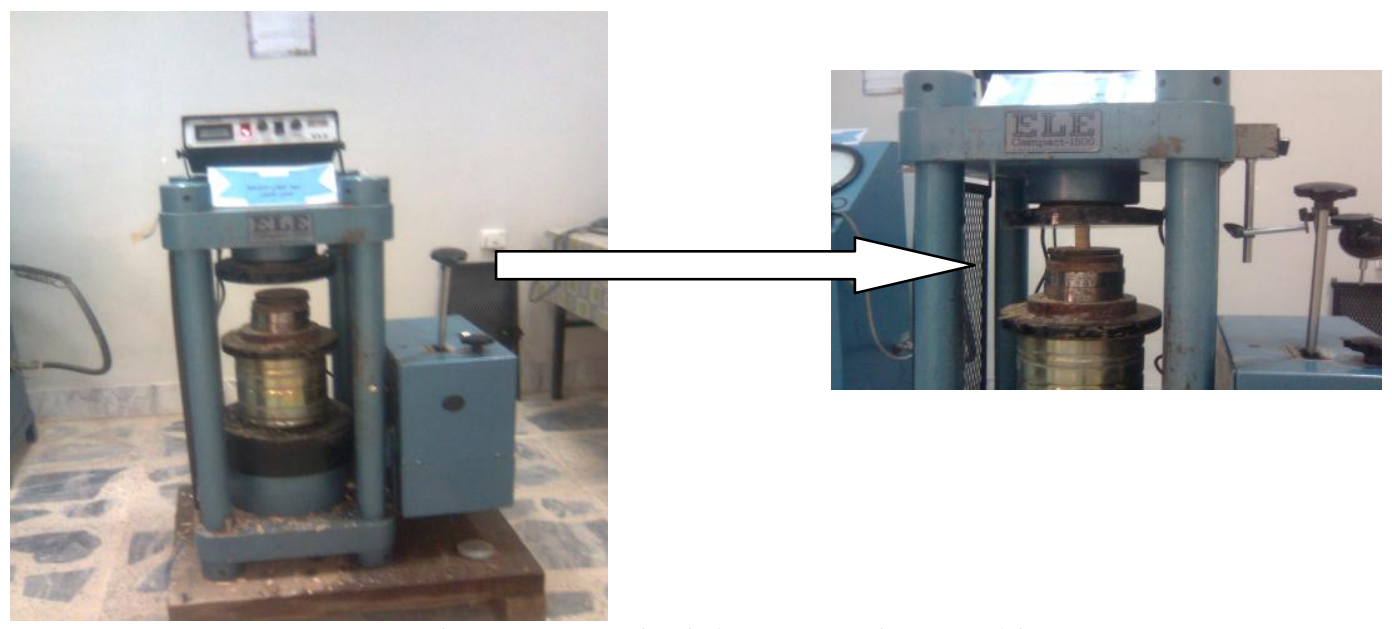

Figure (1): Uniaxial compressive machine.

The surface hardness was made by using Rockwell hardness tester (Brooks inspection equipment LTD /Colchster-England) equipped with an indenter in the form of round steel ball of $1 / 2$ inch in diameter with minor load $10 \mathrm{Kg}$ and major load of $50 \mathrm{Kg} .{ }^{(11,15)}$

The collected data were analyzed using one sample t-test, one way analysis of variances (ANOVA) and Duncan's multiple range test.

\section{RESULTS}

The mean of the amount of water in $\mathrm{ml}$ used by the dentists for each 100gm of powder was $27.89 \mathrm{ml}$ compared to the $25 \mathrm{ml}$ which is the amount recommended by manufacturer.

One sample t-test showed that there is a significant difference between the water powder ratio used by the dentist included in this study and that of the manufacturer at $p \geq 0.5$ (Table1).

Table (1): One sample t-test of powder water ratio used by the dentist and that recommended by manufacturer

\begin{tabular}{lccccc}
\hline Group & N & Mean & Test value & Sig.(2-tailed) & Mean difference \\
\hline Dentist W/P & 20 & 27.89 & 25 & .000 & 2.89 \\
\hline
\end{tabular}


Table (2): Mean and standard deviation for compressive strength and surface hardness

\begin{tabular}{cccc}
\hline Mixing methods & $\begin{array}{c}\text { Compressive strength } \\
\text { Mean } \pm \text { SD }\left({ }^{\mathbf{N} / \mathbf{m m}^{2}}\right)\end{array}$ & $\begin{array}{c}\text { Surface hardness } \\
\text { Mean } \pm \text { SD }\end{array}$ & N \\
\hline MWR & $261.9427 \pm 21.96837$ & $54.7250 \pm 4.94461$ & 4 \\
MPR & $274.6815 \pm 12.83799$ & $64.0250 \pm 15.35065$ & 4 \\
MWZ & $205.4140 \pm 37.90567$ & $64.1000 \pm 11.76350$ & 4 \\
MPZ & $242.8344 \pm 24.02648$ & $84.8250 \pm 16.43135$ & 4 \\
DWR & $204.6178 \pm 41.55410$ & $71.6250 \pm 10.80444$ & 4 \\
DPR & $201.4331 \pm 43.54060$ & $78.3750 \pm 12.48636$ & 4 \\
DWZ & $191.8790 \pm 21.81393$ & $82.8750 \pm 15.80029$ & 4 \\
DPZ & $187.8981 \pm 35.55867$ & $73.8250 \pm 9.67897$ & 4 \\
\hline
\end{tabular}

One way ANOVA showed a significant difference in both compressive strength and hardness between tested groups at $p \geq$ 0.5 (Tables 3, and 4).

Table (3):One way ANOVA of compressive strength

\begin{tabular}{|c|c|c|c|c|c|}
\hline & Sum of squares & df & Mean squares & $\mathbf{F}$ & Sig \\
\hline Between groups & 31487.079 & 7 & 4498.154 & 4.485 & 0.003 \\
\hline Within groups & 24072.985 & 24 & 1003.041 & & \\
\hline Total & 55560.063 & 31 & & & \\
\hline
\end{tabular}

Table (4):One way ANOVA of surface hardness

\begin{tabular}{clccccc}
\hline & Sum of squares & df & Mean squares & F & Sig \\
\cline { 2 - 5 } Between groups & 3003,857 & 7 & 429.122 & 2.67 & .034 \\
Within groups & 3853.313 & 24 & 160.555 & 3 & \\
\hline Total & 6857,170 & 31 & & & \\
\hline
\end{tabular}

Duncan's multiple range tests of both compressive strength and surface hardness showed that there is no significant difference whether the water is added to powder or the powder is added to water. But, it showed a significant difference in compressive strength value between mixing by rubber bowl and spatula and ziplock bag when the manufacture water powder ratio was used in that the MWR and MPR have the a significantly higher compressive strength value but the MWR have a significantly lower surface hardness value compared to other groups, Duncan's multiple range test of surface hardness also showed that using zip-lock method give a significantly higher hardness value than rubber bowl and spatula. (Figures 2, and 3). 


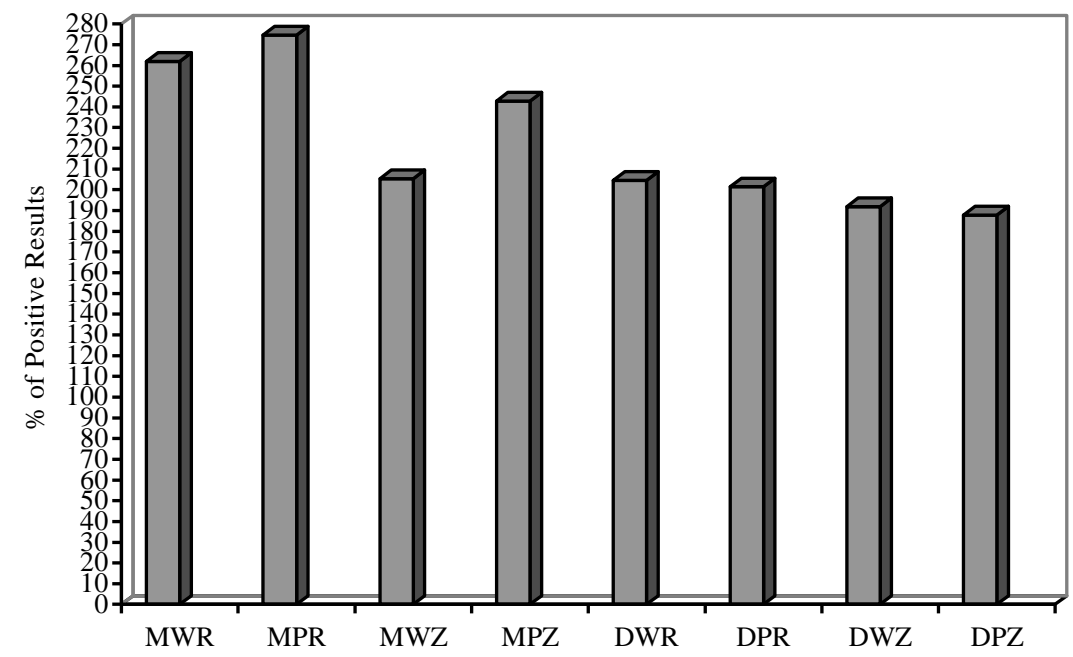

Figure (2): Duncan's multiple range test of compressive strength.

MWR: according to manufacture instruction putting water first mixing by rubber bowel and spatula; MPR; according to manufacture instruction putting powder first mixing by rubber bowel and spatula; MWZ: according to manufacture instruction putting water first mixing by zip-lock bag; MPZ: according to manufacture instruction putting powder first mixing by zip-lock bag; DWR: according to dentists putting water first mixing by rubber bowel and spatula; DPR; according to dentists instruction putting powder first mixing by rubber bowel and spatula; DWZ: according to dentists instruction putting water first mixing by zip-lock bag; DPZ: according to dentists instruction putting powder first mixing by ziplock bag.

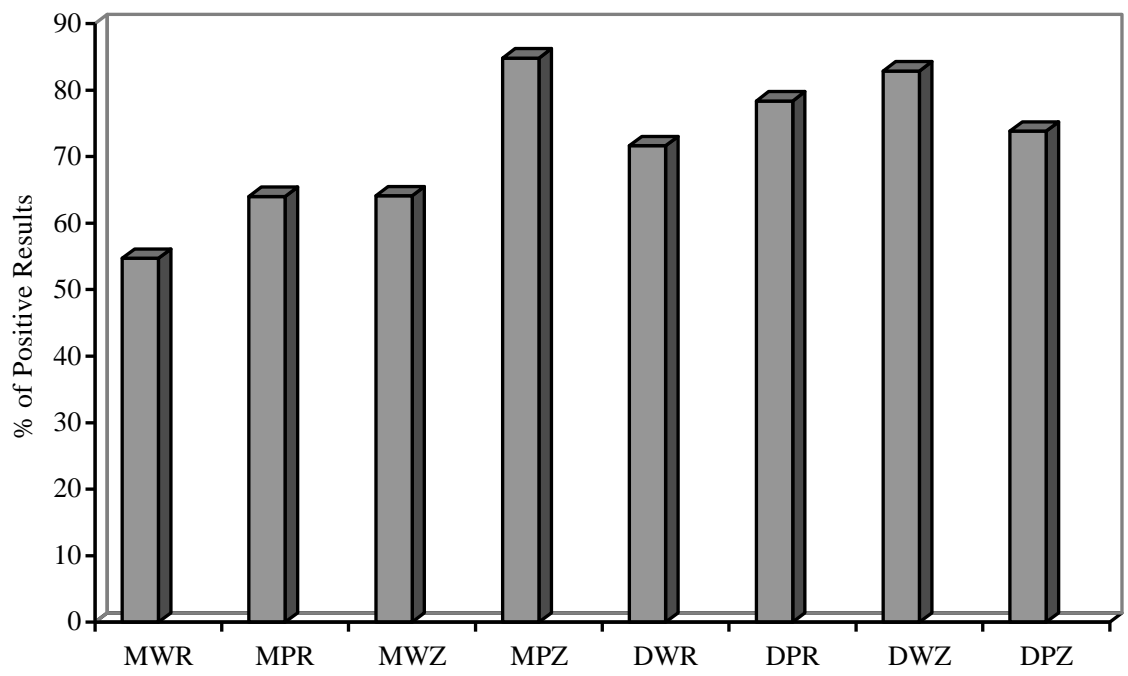

Figure (3): Duncan's multiple range test of surface hardness.

MWR: according to manufacture instruction putting water first mixing by rubber bowel and spatula; MPR; according to manufacture instruction putting powder first mixing by rubber bowel and spatula; MWZ: according to manufacture instruction putting water first mixing by zip-lock bag; MPZ: according to manufacture instruction putting powder first mixing by zip-lock bag; DWR: according to dentists putting water first mixing by rubber bowel and spatula; DPR; according to dentists instruction putting powder first mixing by rubber bowel and spatula; DWZ: according to dentists instruction putting water first mixing by zip-lock bag; DPZ: according to dentists instruction putting powder first mixing by ziplock bag.

\section{DISCUSSION}

The compressive strength of samples that prepared according to water powder ratio recommended by manufacturer which is lower than that used by the dentists showed a significantly higher value than that prepared by using water powder ratio used by dentists this may be attribut- 
ed to the denser material and the compressive strength of gypsum product is inversely related to the water powder ratio and directly related to density of set mass. ${ }^{(16,9)}$

The lower surface hardness could be related to the higher surface porosity ${ }^{(17)}$ so the lower value of surface hardness for the MWB group may attributed to thick mix which made it difficult for the air bubbles to escape from the mix during vibration and result in more porous mix. Considerable quantities of air may be incorporated during mixing and this may lead to porosity within the set material and the strength of gypsum depends, primarily, on the porosity of the set material. ${ }^{(6)}$

According to Combe and $\mathrm{Smith}^{(18)}$ there is no clear relation detected between the value of both hardness and compressive, since the condition of the surface layer determine the former.

\section{CONCLUSIONS}

Mixing by rubber bowl and spatula and using water powder ratio recommended by manufacturer give the highest compressive strength value while using ziplock bag give a higher surface hardness value than rubber bowl and spatula.

\section{REFERENCES}

1. Scrabeck JG, Eames WB. Spatulation methods and porosities in investments and impression material. $J$ Prosthet Dent. 1986; 55: 332-334.

2. Brennan J. Dental Stones for Casting Depressed Shoemarks and Tyremarks. J Forensic Sci Soci. 1983; 23(4): 275285

3. Adair T, Shaw R. The Dry-Casting Method: A reintroduction to a Simple Method for Casting Snow Impressions . J Forensic Ident. 2007; 57(6): 823-831.

4. Pereira C, Costa Santos J, Solheim T. Evidence collection of a tooth mark in a crime scene: importance of the dental materials in forensic dentistry. Revista Portuguesa de Estomatologia, Medicina Dentária e Cirurgia Maxilofacial. 2009; 50:142-144.

5. Cohen A, Wiesner S, Grafit A, Shor Y. A new method for casting three- dimensional shoeprints and tire marks with dental stone. J Forensic Sci. 2011; 56(S1): S210-S213.

6. McCabe JA, Walls AW. Applied dental materials.9th ed., Blackwell Publishing Ltd, 2008; Pp:32.

7. Craig RG. Restorative dental materials 10th ed., Mosby company, 1997; Pp: 333-354

8. Ray N. Dental Materials Sciences. Wilton, Cork, Ireland, 2001; Pp:18-35

9. Craig RG. O'Brien WJ, Power JM. Dental materials 10th ed., Mosby company, 1996; Pp: 156-232,181-199

10. Kaiser DA, Nicholls LT. A study of distortion and surface hardness of improved artificial stone casts. $J$ prosthet Dent. 1976; 36(4): 373-381.

11. Mori $\mathrm{T}$ and Yamane M. Fractography of cast gypsum. Aust Dent J. 1982; 27(3): b30-47.

12. Lidquist TJ ,Stanford CM and Konx E. Influence of surface hardener on gypsum abrasion resistance and water sorption. J Prosthet Dent. 2003; 90(5): 441-6.

13. Al-Shakhily GA. The effect of disinfectant solutions on some properties of dental stone cast. M.Sc. thesis, College of Dentistry, University of Baghdad. 2008.

14. American dental association specification(1974-1975)guide to dental materials and device. Pp: 86-96, 255-260.

15. Mohammed SA. The effect of processing variable on the surface hardness, flow and setting time of gypsum materials. MSc thesis. university of Alabama.1983

16. VonFraunhofer JA, Spiers RR. Strength testing of dental stone :A comparison compressive, tensile, transverse and shear strength tests. $J$ Biomed Mater Res.1983,17(2): 293-9.

17. Ragain JC, Grosko ML, Raj M, Rayan TN, Johnston WM. Detail reproduction, contact angle and die hardness of elastomeric impression and gypsum die material combination. Int $J$ prosthodont 2000;13(3): 214-220.

18. Combe EC, Smith DC. Some properties of gypsum plaster. Brit Dent $J$. 1964; 117(6): 237-14. 